\title{
LA EXPANSIÓN SINTÁCTICA DEL VERBO EN CATALÁN: PROPUESTA DE SISTEMATIZACIÓN
}

\begin{abstract}
Ginebra Serrabou Jordi, Montserrat Ciurana Anna, La expansión sintáctica del verbo en catalán: propuesta de sistematización [Syntactic 'expansion' of the Catalan verb: a proposal of systemisation]. Studia Romanica Posnaniensia, Adam Mickiewicz University Press, Poznań, vol. XXXI: 2004, pp. 277-285. ISBN 83-232-1353-4, ISSN 0137-2475.
\end{abstract}

Syntactic information has been traditionally neglected in lexicographical compendia. This paper seeks to show what aspects of syntax have to be taken into account when planning a verbs dictionary and how this information can be offered systematically to guide normal users in building correct messages.

To exemplify both these initial problems and how to solve them, we use the workfiles of the only dictionary on verbal information, the Diccionari d'ús dels verbs catalans, published in 1999, of which we are the authors.

La presente comunicación está íntimamente ligada a la elaboración del Diccionari d'ús dels verbs catalans (en adelante DUVC) (Ginebra, Montserrat, 1999) y pretende dar cuenta, sobre la base de ejemplos puntuales, de los problemas taxonómicos que se plantean ante la elaboración de una obra de este tipo, así como de algunas propuestas de sistematización del régimen verbal que en ella se recogen'.

La tradición lexicográfica románica no ha mostrado una excesiva preocupación por tratar con rigor y coherencia, en los artículos de diccionario, los aspectos relacionados con el régimen verbal, a pesar de su indiscutible carácter gramatical y carácter léxico. Los patrones de dichos artículos se han ido transmitiendo de obra en obra con pocas -y lentas- mejoras cualitativas. Podemos considerar que en catalán

\footnotetext{
${ }^{1}$ Parte de la investigación subyacente ha sido realizada en el marco del proyecto financiado por la Dirección General de Enseñanza Superior e Investigación Científica (número de referencia PB981517). Asismismo los autores pertenecen al Equip de Recerca en Llengua, Estructura i Ús de la Universidad Rovira i Virgili.
} 
los compendios lexicográficos prácticamente no se han ocupado de la sintaxis verbal hasta 1999.

Es de desear que un diccionario de uso del régimen verbal, dirigido al usuario medio y no restringido al lingüista, describa en toda su extensión la expansión sintáctica ${ }^{2}$ de cada verbo, con sus estructuras intrínsecas y sus posibilidades de combinatoria, junto con el carácter obligatorio, opcional o alternativo de los complementos. Para conseguir tal objetivo descriptivo no especializado, debe reunir, entre otros, los siguientes requisitos:

- Aportar una ejemplificación exhaustiva, incluso más allá de lo que se considera la estricta expansión, sobre todo ante usos vacilantes; una ejemplificación fundamentada en un extenso corpus de fuentes primarias y secundarias, en la normativa oficial y en las opiniones de gramáticos autorizados.

- Presentar la información de forma visualmente simple, tanto desde el punto de vista tipográfico como evitando el uso del metalenguaje propio de la especialidad, incluso omitiendo términos relativamente básicos como verbo transitivo, pronominal, etc.

Asismismo, y a pesar del indudable peso de la sintaxis sobre la semántica en la redacción de las entradas, cabe esperar que un diccionario actual aplique las convenciones lexicográficas vigentes, tales como evitar la circularidad y las definiciones múltiples, aislar la definición estricta de los complementos de régimen propiamente dichos y lograr definiciones parafraseables (aislando los elementos de régimen si es imprescindible que aparezcan).

\section{II}

En este sentido, el trabajo propiamente descriptivo de la elaboración del DUVC nos ha exigido la revisión de bases teóricas como el límite mismo del concepto de régimen y su aplicación lexicográfica y, ya con más detalle y a título de ejemplo, aspectos como los siguientes:

1. Las estructuras que se pueden englobar bajo la denominación de complemento directo, o que en cualquier caso cumplen la condición de sintagmas nomi-

${ }^{2}$ Entendemos que el término expansión, ya utilizado en algunas obras teóricas sobre sintaxis, es suficientemente transparente. A grandes rasgos, equivale al término contorno, usado por Manuel Seco en su Diccionario del español actual. En cualquier caso, cuando hablamos de expansión de un verbo, nos referimos a todos aquellos complementos no circunstanciales con que un verbo se construye obligatoriamente o se puede construir opcionalmente, también llamados fuertes, nucleares, argumentales, subcategorizadores o de primer nivel. Por eso consideramos básica la superación del concepto de obligatoriedad a favor del de exigencia para identificar a tales complementos regidos. No se trata tanto de los complementos fuertes aparecen obligatoriamente junto al verbo (como por ejemplo en consistir) sino más bien de aquéllos que de llevarlos, el verbo exige que sean de un determinado tipo: menjar (comer) + complemento directo, arribar (llegar) + complemento directivo, trobar-se (encontrarse) + complemento modal, etc, aunque en algunos el verbo pueda presentar un uso absoluto. 
nales sin preposición (o con la preposición pertinente según las reglas gramaticales) directamente exigidos por el verbo, tales como los pasivizables tradicionales, los complementos del verbo tener y similares o los de peso y medida. Asimismo se ha planteado la necesidad de indicar los posibles usos absolutos de verbos transitivos, usos que en algunos casos presentan claras limitaciones estructurales, y la necesidad de una nueva subentrada para casos en que el uso absoluto comporta un cambio de definición: beure, obrir.

2. El límite entre los complementos indirectos propiamente exigidos por el verbo, que a grandes rasgos coinciden con los llamados dativos léxicos (agradar, oferir) y los que no lo son (que no incluímos en la expansión pero sí como ejemplos), normalmente equivalentes a un posesivo o a dativos éticos, benefactivos o de interés. En este grupo también nos planteamos la posibilidad de que el verbo presente un uso absoluto, con más restricciones sintáctico-formales que en el caso del directo (Són coses que dolen) o que el dativo aparezca como único complemento, ya sea por exigencia (Li agrada el jazz) u opcionalmente (Les gallines no li ponen).

3. Los distintos tipos sintáctico-semánticos de complemento predicativo, de los cuales los tres primeros se pueden considerar regidos y el cuarto, no regido: Les aigües baixen tèrboles, equivalente a un complemento modal con concordancia en verbos no atributivos; Nomenaran coordinadora la Laura, elemento de un doble acusativo; Els va tractar de lladres, equivalente a un complemento preposicional pero con concordancia, y Va arribar victoriosa a la ciutat, en que, como hemos apuntado, la presencia de otro complemento regido, en este caso un locativo, convierte al predicativo en no regido.

4. La necesidad de distinguir entre complementos locativos, temporales y modales circunstanciales y regidos, distinción que aún hoy presenta muchas irregularidades en los tratados y manuales de gramática. En este sentido, consideramos claramente regidos los complementos de los enunciados siguientes: Aquesta tarda arriben de Cracòvia, Fes el favor de portar-te bé, L'àmfora data del segle XII.

\section{III}

En el segundo bloque de esta comunicación pormenorizamos una propuesta de trabajo previa a la redacción del DUVC, relativa a los verbos pronominales, y cuatro ejemplos de formalización de diversos aspectos.

1. En relación con los verbos calificados grosso modo como pronominales, los autores del DUVC trataron de establecer una base teórica que aislara claramente

${ }^{3}$ Retomando lo precisado en la nota 2, podemos corroborar que el concepto de obligatoriedad es aplicable a los dos últimos ejemplos, mientras que el de exigencia, que es el que en realidad determina lo regido, es aplicable a los tres. 
este tipo de verbos respecto a otras construcciones con pronombre en las cuales éste desempeñara una función léxica. De los primeros había que dar cuenta de modo exhaustivo en el diccionario, presentando su casuística estructural, mientras que los segundos únicamente podían aparecer como ejemplo de uso en las entradas, pero no como construcción tipificada. La única excepción a este criterio la protagonizan las construcciones ergativas: aunque semánticamente diferenciados de los verbos pronominales estrictos, la coincidencia formal entre unos y otros nos condujo a no representarlos aisladamente, dado el objetivo fundamental del diccionario de orientar en el uso al usuario medio, por encima del lingüista o el profesional.

Establecida esta base teórica, que presentamos en el cuadro 1, había que regularizar las incongruencias que en este respecto padecían las obras de referencia, en las cuales no aparecían numerosas equivalencias pronominales de verbos transitivos (o aparecían en una entrada que no correspondía) y, en menor medida, equivalencias transitivas de verbos pronominales. Finalmente era preciso intentar regularizar las discrepancias entre normativa y uso, con el agravante de que a menudo la normativa en este sentido es incompleta y bastante restrictiva y el uso es vacilante, interferido por el español en una parte nada menospreciable de la población.

Cuadro 1

\section{Verbos pronominales}

- Verbos pronominales con -se que no llevan complementos: Si no t'acotxes, no passaràs per la porta.

- Verbos pronominales con -se que no llevan complementos y que presentan el pronombre como opcional, es decir, su ausencia no es relevante semánticamente: La reunió de la junta de veïns (es) va acabar molt tard.

- Verbos pronominales con complemento directo: Es va empassar el xiclet sense voler o bien con complemento preposicional: Si fa bo, ens arribarem a Tarragona.

- Verbos pronominales con complementos, que presentan el pronombre como opcional, es decir, su ausencia no es relevante semánticamente: S'estima sa mare amb bogeria.

- Verbos pronominales que aparecen con otros clíticos que no son -se o bien combinados con éste: haver-hi, veure-hi, anar-se'n, tornar-se'n; ballar-la, espifiar-la. 
- Verbos léxicamente recíprocos: L'acusat i el testimini s'acaren. L'acusat s'acara amb el testimont.

- Verbos ergativos: Amb aquest rum-rum monòton del viatge m'he abaltit.

\section{Construcciones (que no aparecen en la expansión pero sí en los ejemplos)}

- Construcciones reflexivas directas: S'odiava per haver-la deixat escapar.

- Construcciones reflexivas indirectas: Com que ningú em regala el llibre, me'l regalaré jo.

- Construcciones recíprocas directas: La Laia i l'Amadeu no s'estimen.

- Construcciones recíprocas indirectas: Vols que ens escriguem missatges electrònics?

- Construcciones de dativo posesivo: La Pepa es toca la cara.

- Construcciones pasivas reflejas: El tema es debat avui.

- Construcciones de sujeto indeterminado: Es diu que no hi ha diners.

2. En el cuadro 2 presentamos una de las aportaciones más novedosas del DUVC, la formalización lexicográfica de lo que denominamos "verbos con pronombre obligatorio", resultado de observar que hay un grupo de verbos que se caracterizan porque siempre llevan un pronombre referencial aunque no sean propiamente verbos pronominales; y esto con independencia de que el pronombre coexista con un complemento realizado léxicamente (en cualquier posición pero preferentemente antepuesto al verbo). Lo ilustran los siguientes enunciados, pertenecientes a distintos grados de formalidad:

A la noia dels pantalons negres li diuen Lídia.

A la Raquel se li ha entravessat el professor nou de química.

${ }^{4}$ En estos casos la descripción sintáctica es relativamente compleja, dado que el sujeto es necesariamente birreferencial y que se establece en él una relación de reciprocidad. Se ha considerado que los verbos léxicamente recíprocos tienen asimismo una versión unirreferencial, versión que aunque aparezca con la misma definición que la anterior constituye una subentrada independiente. Traducido a la expresión formal, ello significa que en estos verbos se prevé la doble posibilidad de sujeto plural o coordinado, y a la vez la opción de que uno de los sujetos semánticos se revista formalmente de complemento del verbo:

acoblar <un animal (expressat en plural o coordinant els elements)> Copular l'un amb I'altre. Els mamífers s'acoblen durant una època de l'any. El bóc i la cabra s'han acoblat. 5. acoblar-se [amb un animal] <un animal> Copular. El bóc s'acobla amb la cabra. 
A la Montsant se li ha escapat un secret regròs.

Al director ja li va bé l'estudi que hem fet.

En això d'ajudar-te a buscar feina no hi pot fer més.

A l'Allcia li esdevingué que de sobte es va trobar en un altre pats.

Cuadro 2

8. entrar [a algú (expressat per un pronom feble)] <una cosa> Sobrevenir. $L i$ va entrar un dubte, una sospita. M'han entrat nervis. Quina dropada que m'ha entrat! (El complement, que apareix obligatòriament amb la forma pronominal $\mathrm{li}$, pot anar acompanyat d'un complement ple: $A$ la Júlia de sobte li ha entrat una gran tristesa.)

3. Finalmente en el cuadro 3 confrontamos las entradas de tres verbos (insistir, postular y chutar) en las obras de referencia hasta la aparición del DUVC con el mismo DUVC.

En una primera aproximación ya podemos constatar que los diccionarios generales de referencia (DIEC y GDLC) aportan pocos datos en lo que a información recciográfica se refiere. Por una parte, apenas proporcionan ejemplos de uso, lo cual resulta especialmente problemático en verbos cultos con distintas acepciones de matiz, desconocidas a grandes rasgos por el usuario medio como es el caso de postular. Lo mismo sucede con algunas acepciones arcaicas o en retroceso, que se repiten de unas obras a otras sin verificar su uso actual y sin aportar ejemplos, como en la primera acepción del verbo insistir. Por otra parte, tanto el DIEC como el GDLC, cuando ejemplifican, to hacen parcamente y sin atender a la rica variedad sintáctica que algunos verbos presentan en sus complementos. Tal es él caso del fenómeno conocido como "cambio y caída de preposición", que, como en insistir, afecta a verbos cuyo complemento preposicional sufre unas determinadas modificaciones en función de si se trata de un sintagma nominal, una construcción de infinitivo o una oración. Siendo éste uno de los puntos flacos en el conocimiento de la norma por parte de los hablantes, los diccionarios deberían recogerlo de modo sistemático. Más restrictivo todavía nos parece el tratamiento del verbo chutar. En primer lugar, se presenta únicamente como intransitivo, negando por lo tanto la posibilidad de construir frases en las que la pelota o el balón son precisamente el complemento directo. Y más allá: no se contempla la posibilidad de que se puedan chutar otros objectos aparte del balón o la pelota, como por ejemplo piedras o latas de refresco. Finalmente se suelen omitir los usos y acepciones más recientes, en su mayoría coloquiales pero también en algunos casos especializados, que, toda vez que son usados de forma creciente por la población, requieren también una fijación recciográfica.

En la columna tercera mostramos nuestra propuesta de sistematización para subsanar las carencias planteadas. 


\begin{tabular}{|c|c|c|}
\hline DIEC $1995^{5}$ & GDLC $1998^{6}$ & DUVC 1999 \\
\hline $\begin{array}{l}\text { insistir } v \text {. intr. Una cosa, descansar sobre } \\
\text { una altra. \| Perseverar a dir, a fer, etc., } \\
\text { esp. a demanar. Ell insistia en el seu } \\
\text { propòsit. Es inútil que insisteixis: no } \\
\text { aconseguird̀s el que demanes. }\end{array}$ & $\begin{array}{l}\text { insistir (1344; del ll. insistere, íd. [v. assistir]) v intr } 1 \\
\text { Descansar una cosa sobre una altra. } 2 \text { Perseverar a dir, a } \\
\text { fer, etc, especialment a demanar. Ell insistia en el seu } \\
\text { propòsit. És inútil que insisteixis. }\end{array}$ & $\begin{array}{l}\text { insistir l. insistir (a algú) (en una cosa o bé a +oracio d'infinitiu o bé } \\
\text { que + oració) Perseverar, tornar a dir o posar èmfasi. No insisteixi: no } \\
\text { diré res. No insisteixis en aquest tema perquè no te'n diré res més. } \\
\text { Insistiu en la formulació, perquè és la part que costa més als alumtes. } \\
\text { Insisteix a demanar-li augment de sou tot i que sap que no s'ho mereix. } \\
\text { Encara li insistia que anés de viatge amb ella, després del que li va fer? }\end{array}$ \\
\hline $\begin{array}{l}\text { postular } v . t r . \text { Demanar amb insistència } \\
\text { (esp. càrrecs, beneficis); acaptar. \|| } \\
\text { Demanar com a prelat d'una església una } \\
\text { persona que per dret no pot ésser elegida. | } \\
\text { Un postulador, pledejar una causa de } \\
\text { beatificació o de canonització. | Demanar } \\
\text { d'ésser admès en un orde religiós. \|| } \\
\text { Formular un postulat. }\end{array}$ & $\begin{array}{l}\text { postular (1344; del ll. postulare 'demanar') v tr } 1 \\
\text { Demanar amb insistència, sol-licitar un càrrec, un } \\
\text { privilegi. } 21 \text { Acaptar. } 2 \text { esp CATOL Demanar almoina } \\
\text { els religiosos que per a aixo ha designat un orde o una } \\
\text { congregació religiosa. } 3 \text { DR CAN } / \text { Demanar com a prelat } \\
\text { d'una església una persona que per dret no pot ésser } \\
\text { elegida. } 2 \text { Pledejar un postulador una causa de } \\
\text { beatificació o de canonitzacio. } 3 \text { Demanar d'Esser adraès } \\
\text { en un orde religiós. } 4 \text { FILOS/LOG Formular un postulat. } \\
\end{array}$ & $\begin{array}{l}\text { postular 1. postular <un religiós> Demanar almoina amb finalitat } \\
\text { pietosa. Era franciscd i postulava per a l'orde. 2. postular [una causa de } \\
\text { beatificacio o canonizzacio] Defensar (davant un tribunal eclesiàstic). El } \\
\text { sacerdot que va postular la causa de la mare Molas era un bon } \\
\text { canonista. 3. postular [que + oració] Admetre com a postulat. La } \\
\text { biologia postula que la vida existeix: no pretén demostrar-ho. 4. postular } \\
\text { [en un orde religiós] Demanar ser admès. El seu germà ha postulat en un } \\
\text { orde fundat a Amèrica. La tia Lourdes havia postulat a les carmelites de } \\
\text { ben joveneta. }\end{array}$ \\
\hline $\begin{array}{l}\text { xutar v. intr. Colpejar la pilota anb el } \\
\text { peu. }\end{array}$ & $\begin{array}{l}\text { xutar }\left(\text { de } x u t^{2}\right) \text { v intr ESPORT Colpejar el balo o pilota } \\
\text { amb el peu. }\end{array}$ & $\begin{array}{l}\text { xutar 1. xutar [una cosa] Donar un cop amb el peu. No hi ha ningú que } \\
\text { xuti la pilota amb tanta elegancia com tu. Molt enfadada, anava xutant } \\
\text { tots els joguets que trobava pel camt. Va xutar la pilota al porter de } \\
\text { l'equip contrari. 2. xutar (a un lloc) Donar un cop a la pilota amb el peu. } \\
\text { Xuta, corre, ara és el moment' El porter no pot xutar directament a } \\
\text { l'altra porteria. El davanter va xutar enrere cap a l'àrea propia. } 3 \text {. } \\
\text { xutar-se (droga) Injectar-se. Va arribar a xutar-se das cops al dia. Està } \\
\text { tan desesperat que es xutaria qualsevol merda. }\end{array}$ \\
\hline
\end{tabular}

${ }^{5}$ Diccionari de la llengua catalana, del Institut d'Estudis Catalans, en el apéndice.

${ }^{6}$ Gran diccionari de la llengua catalana, de Enciclopèdia Catalana, en el apéndice. 


\section{APÉNDICE}

Al no ser el catalán una de las lenguas más conocidas por los romanistas, e incluso por los hispanistas, presentamos para concluir una lista de obras de consulta que creemos útiles para aquéllos que estén interesados en ahondar en el tema expuesto $^{7}$.

\section{BIBLIOGRAFÍA TEÓRICA Y DESCRIPTIVA (SELECCIÓN)}

Bonet, S., Solà J. (1986), Sintaxi generativa catalana. Barcelona: Enciclopèdia Catalana.

Branchadell, A. (1992): A Study of Lexical and No-Lexical Datives. Universitat Autònoma de Barcelona [tesis doctoral inédita].

-(1993), La naturalesa categorial de l'objecte indirecte, Els Marges, núm. 48 (junio), 101-109.

- (1994-1995), La identitat formal dels datius lèxics i no-lèxics, Llengua \& Literatura, núm. 6, 233-251.

Cano Aguilar, R. (1981), Estructuras sintácticas transitivas en el español actual. Madrid: Gredos.

Ginebra, J. (1988), Règim, en Antoni de Bofarull $i$ la Renaixença. Reus: Associació d'Estudis

Reusencs, 260-269.

- (1996), Classificació sintàctica del verb. Règim verbal, en L'obra gramatical d'Antoni Febrer i

Cardona (1761-184I). Maó: Institut Menorquí d'Estudis, 135-138.

Gràci a, L. (1989), Els verbs ergatius en català. Maó: Institut Menorquí d’Estudis.

- (1989), La teoria temàtica. Bellaterra: Publicacions de la Universitat Autònoma de Barcelona.

Haegeman, L. (1993), Teoria de la recció i del lligam. Barcelona: Enciclopèdia Catalana.

Lorente, M. (1996), La teoria de l'estructura argumental i la representació del lèxic, en Actes del

Desè Col-loqui Internacional de Llengua i Literatura Catalanes. Frankfurt am Main, 18-25 de setembre de 1994, a cargo de Axel Shonberger i Tilbert Dídac Stegmann, vol. III. Barcelona: Publicacions de l'Abadia de Montserrat, 323-335.

Sol Salvadó, L. (1992), El DGLC i la formalització lexicogràfica dels verbs. Universitat de Barcelona [tesis de licenciatura inédita].

Solà, J. (1977), Test a quatre diccionaris, en A l'entorn de la llengua. Barcelona: Laia, 141-145.

- (1987), El Diccionari general de la llengua catalana, en L'obra de Pompeu Fabra. Barcelona: Teide, 111-125.

- (1994), La lexicografia general i la normativa, Caplletra, núm. 17, 273-290.

\section{DICCIONARIOS GENERALES}

Alcover, A. M., Moll F. B. de (1926-1962), Diccionari català-valencià-balear, 10 vol. Palma: Editorial Moll.

Coromines, J. (1980-1991), Diccionari etimològic i complementari de la llengua catalana, 9 vol. Barcelona: Curial / La Caixa.

Diccionari de la llengua catalana (1995), Barcelona: Enciclopèdia Catalana / Edicions 62. Fabra, P. (1932), Diccionari general de la llengua catalana. Barcelona: Llibreria Catalònia.

${ }^{7}$ Asimismo consignamos una dirección de correo electrónico para facilitar el intercambio de información: amontseratc@uoc.edu. 
Gran diccionari de la llengua catalana (1998). Barcelona: Enciclopèdia Catalana.

Lacreu, J. (dir.) (1995), Diccionari valencià. València: Generalitat Valenciana / Institut Interuniversitari de Filologia Valenciana / Edicions Bromera.

López del Castillo, L. (1998), Diccionari complementari del català normatiu. Barcelona: Edicions 62.

-(dir.) (2000), Gran diccionari 62 de la llengua catalana. Barcelona: Edicions 62.

\section{OBRAS DE GRAMÁTICA NORMATIVA (SELECCIÓN)}

A bril, J. (1997), Diccionari pràctic de qüestions gramaticals. Barcelona: Edicions 62.

Badia i Margarit, A. M. (1994), Gramàtica catalana. Descriptiva, normativa, diatòpica, diastràtica. Barcelona: Enciclopèdia Catalana.

Badia, J., Brugarolas, N., Torné, R., Fargas, X. (1997), El llibre de la llengua catalana. Barcelona: Castellnou Edicions.

Bruguer a, J. (2000), Diccionari de dubtes i dificultats del català. Barcelona: Enciclopèdia Catalana.

Casellas, D., Marquet, L. (1998), Resolguem dubtes. València: Edicions Tres i Quatre.

Coromina, E. (1991), Manual de redacció i estil. El 9 nou, Vic: Eumo.

Documents de la Secció Filològica III (1996). Barcelona: Institut d'Estudis Catalans.

El català a TV3. Llibre d'estil (1995). Barcelona: Televisió de Catalunya, Edicions 62.

Fabra, P. (1956), Gramàtica catalana. Barcelona: Teide.

Lacreu, J. (1990), Manual d'ús de l'estàndard oral. València: Universitat de València / Institut de Filologia Valenciana.

López del Castillo, L. (1999), Gramàtica del català actual. Barcelona: Edicions 62.

Mestres, J. M., Costa, J., Oliva, M., Fité, R. (2000), Manual d'estil. La redacció i l'edició de textos. Vic/Barcelona: Eumo Editorial/Universitat de Barcelona/Universitat Pompeu Fabra/Associaci6 de Mestres Rosa Sensat ( $2^{2}$ edición, corregida).

Morey, J., Melià, J., Corbera, J. (1995), Alfa. Mètode d'autocorrecció gramatical assistida. Palma: Universitat de les Illes Balears.

Pajoma, D., Rico, A. (1998), Diccionari de dubtes del català. Barcelona: Edicions 62.

PREMSA Catalana (1997), Llibre d'estil del diari Avui. Barcelona: Empúries.

Ruaix, J. (1996), Diccionari auxiliar. Moià: J. Ruaix Autor-Editor.

Solà, J. (1994), Sintaxi normativa: estat de la qüestió. Barcelona: Empúries. (2edición, conregida y aumentada),

- (dir.) (1995), Libre d'estil de l'Ajuntament de Barcelona. Barcelona: Consorci per a la Normalització Lingüística / Ajuntament de Barcelona.

- (1999), Parlem-ne. Barcelona: Enciclopèdia Catalana.

- (dir.) (2002), Gramàtica del català contemporani. Barcelona: Empúries.

\section{DICCIONARIOS DE REGIMEN VERBAL}

Ginebra, J., Montserrat, A. (1999), Diccionari d'ús dels verbs catalans (con la colaboración de Xavier Rull y Anna Saperas). Barcelona: Edicions 62. 